\title{
Safety Measurements and Risk Assessment of Coal Mining Industry Using Artificial Intelligence and Machine Learning
}

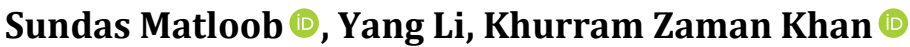 \\ School of Economics and Management, Anhui University of Science and Technology, Huainan, China \\ Email: sundasmatloob@outlook.com,y321212@163.com,khurramzk@outlook.com
}

How to cite this paper: Matloob, S., Li, Y., \& Khan, K. Z. (2021). Safety Measurements and Risk Assessment of Coal Mining Industry Using Artificial Intelligence and Machine Learning. Open Journal of Business and Management, 9, 1198-1209. https://doi.org/10.4236/ojbm.2021.93064

Received: March 24, 2021

Accepted: May 18, 2021

Published: May 21, 2021

Copyright $\odot 2021$ by author(s) and Scientific Research Publishing Inc. This work is licensed under the Creative Commons Attribution International License (CC BY 4.0).

http://creativecommons.org/licenses/by/4.0/

\begin{abstract}
Safety is a legal requirement of mining industry. Effective safety measurements and risk management can serve the mine administration to lessen the dangers recognized in the mine. Autonomous technologies, such as Artificial Intelligence (AI) and Machine Learning (ML) models have been integrated with the mining industry to ensure a safe working environment since a decade ago in the form of fully unmanned workfaces and mining robots. These autonomous technologies provide effective risk assessment as well as many economic profits such as cost reduction, continuous production, reducing labors exposure in dangerous environments, and enhanced protection. The main objective of this paper is to highlight the unidentified hazards during mining and find the solutions to those hazards by using AI and Machine Learning. In addition, this paper will also contribute a worthy resource for explaining the AI advancements in risk assessment in the mining industry. Another advantage of this paper is to fill the gaps in modern techniques and $\mathrm{AI}$ advancements in the safety measurements of coal mining industry.
\end{abstract}

\section{Keywords}

Artificial Intelligence, Smart Mining, Risks Assessment, Coal Mining, Economic Benefits

\section{Introduction}

Risky behavior, risky conditions, and unsafe factors make the mining industry unsafe. Due to its complicated workflow, mining is considered the most dangerous mechanism. According to the MSHA's fatality reports, deaths usually occurred due to falling from the roof, slipping, or tripping, powered haulage and 
falling on the face, rib, side or highwall. If we compare the fatalities in coal industry with other industries, then coal mining can be considered as one of the most dangerous industries (U.S. Department of Labor, n.d.-b: p. 1). It can be seen in the chart that fatality rates from 2017 to 2019 are decreasing due to inventions of new technology in coal mining. According to the research proposed by different organizations such as MSHA, DGMS and World Coal Association, complete removal of dangers is unavoidable in mining although they can be reduced. To reduce the accidents in mines, AI and Machine Learning were used over the last few decades. Risk management reduces hazard, by recognizing uncertainties and executing directions at the time of mining. The decision-making is based on risk assessment in the coal industry, which means that without an effective risk assessment we cannot eliminate hazards underground (Tripathy \& Ala, 2018). Many research papers were written by DGMS, Ericson, Glossop, Loannides, \& Gould, Mullaito to identify the effective risk assessment techniques. A summary of those risk assessment techniques is given in Table 1.

MSHA's fatality reports from 2007 to 2021 raise some key factors such as risky practices, the workers' risky actions, unfit tools, or risky working circumstances (U.S. Department of Labor, n.d.-a: p. 1). It means that sources of the hazards are already identified by different articles and even by some major departments. This research tries to reduce all these hazards present in underground coal mining by using recent AI advancement. Number of Fatal Injuries in the US mining industries in 2017, 2018 and 2019 can be seen in Figure 1. Now let us talk about global market value of coal industry.

The mining industry plays a vital role in the global economy. The market value of coal mines has varied significantly since 2010. In the year 2011 its market value increased to 1.3 billion US dollars, but afterward gradually decreased to 571 million US dollars till 2015. By 2020, the market value was approximately 698 million US dollars (Garside, 2021). Global market value of coal mining from 2010 to 2020 can be seen in Figure 2.

As the population increases, so does the demand for energy. Coal can play a potential role to meet the growing demand of energy. We did a statistical review of global energy consumption of coal with other sources of energy in 2019 in Figure 3. In modern times, people usually prefer other biofuels instead of coal. Havva Balat said that coal demand will be more than $34 \%$ of the world's primary

Table 1. Common risks assessment techniques.

\begin{tabular}{|c|c|c|}
\hline \multirow{2}{*}{ Approach } & \multicolumn{2}{|c|}{ Risk Assessment Techniques } \\
\hline & Formal Approach & Informal Approach \\
\hline & $\begin{array}{l}\text { Workplace Risk Assessment and Control } \\
\text { (WRAC) }\end{array}$ & Failure Mode and Effects Analysis \\
\hline & Fault Tree Analysis & Personal Reflections, Interviews \\
\hline & Hazard Identification and Ranking (HIRA) & $\begin{array}{c}\text { Safety Committee Meetings Safety } \\
\text { Audits }\end{array}$ \\
\hline
\end{tabular}




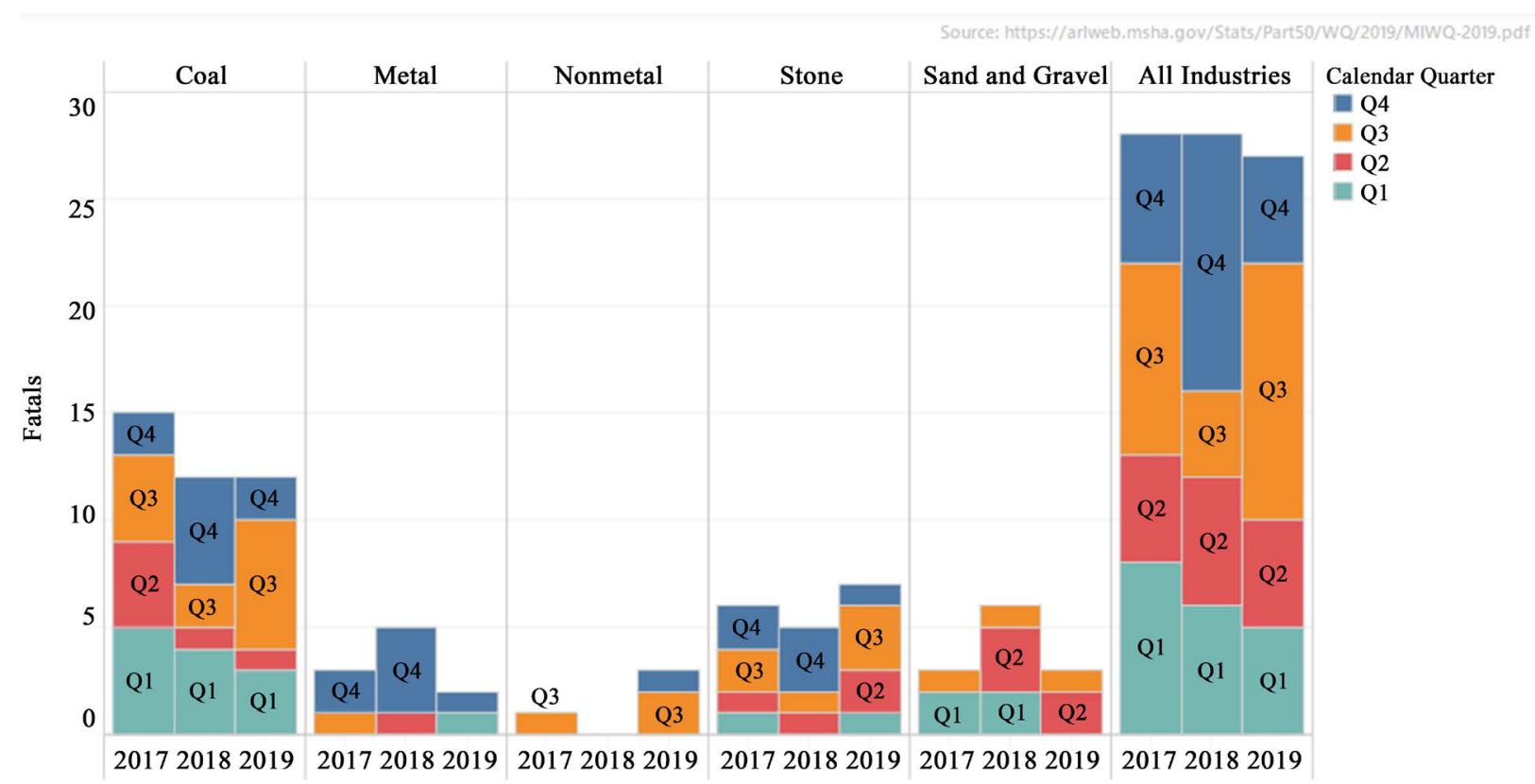

Figure 1. Number of Fatal Injuries in the US mining industries 2017, 2018 and 2019.

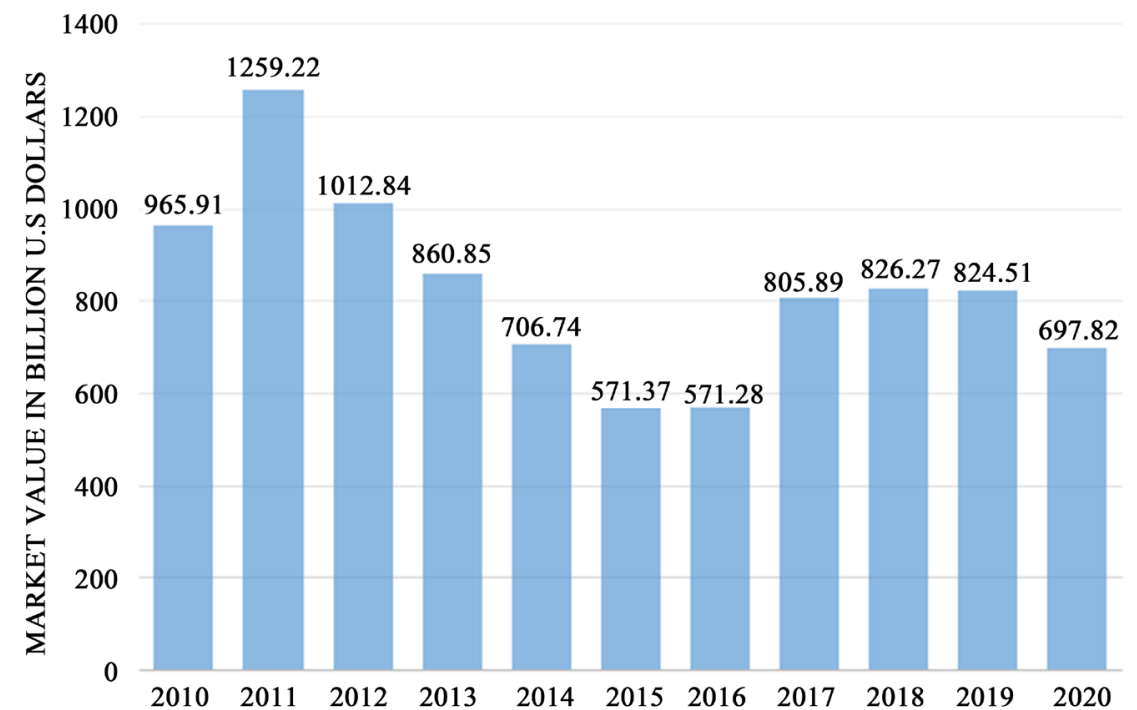

Figure 2. Global market value of coal mining from 2010 to 2020. Figure Source: https://www.statista.com/statistics/1137437/coal-mining-market-size-worldwide/.

energy demand in 2050 (Balat, 2007).

The major coal-producing countries are not limited to specific region, the top five coal producers are China, India, USA, Indonesia, and Australia. Most of the coal productions in the said countries are being consumed by themselves and only a fraction of production i.e., $15 \%$ of solid coal production is exported to the international coal market.

Some of the useful results of the mining industry include revenue opportunities, multi-dimensional influences on the environment, infrastructural developments, and society development. Now comes to the core part of this paper; how 


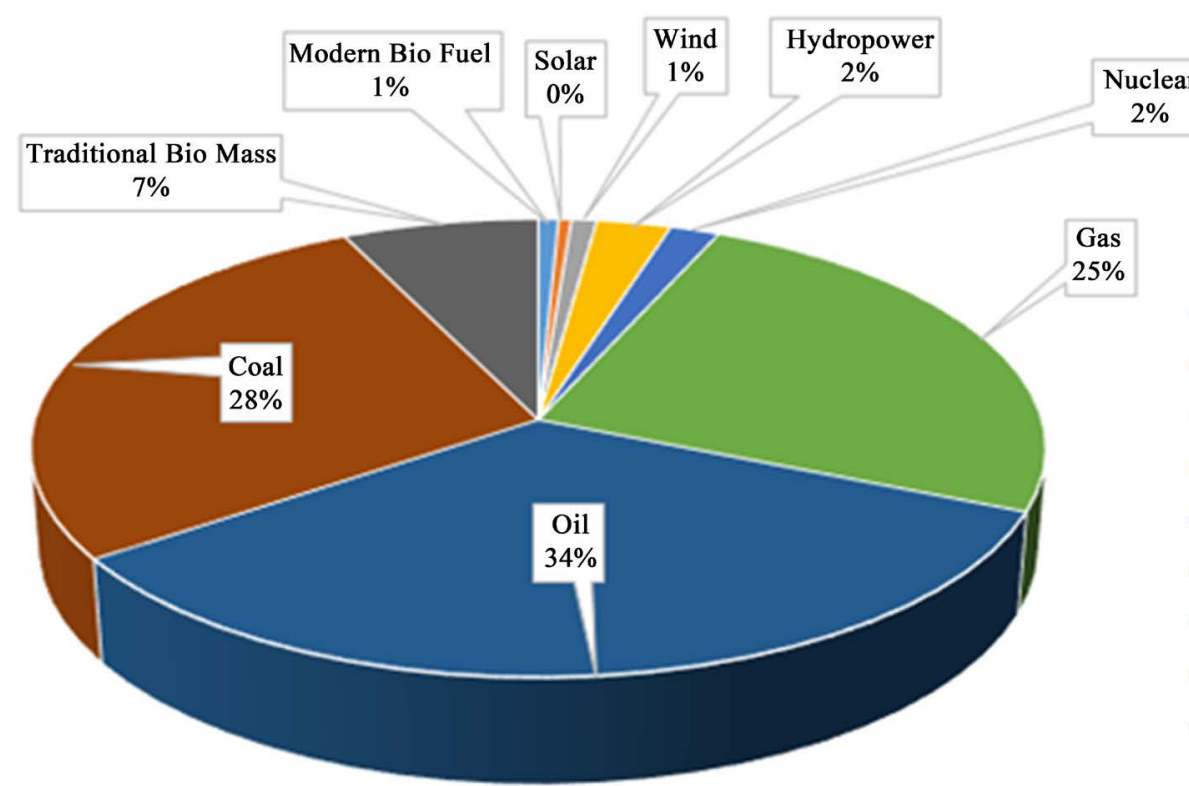

- Modern Bio Fuel

- Solar

- Wind

Hydropower

- Nuclear

$=$ Gas

- Oil

- Coal

- Traditional Bio Mass

Primary Energy Consumption in 2019

Figure 3. Number of Fatal Injuries in the US mining industries 2017, 2018 and 2019.

can AI boost safety in coal mines? AI can access the coal in hard-to-reach places and the use of sensors can alert workers about critical situations. The main idea behind $\mathrm{AI}$ is to collect and share real-time data by using different algorithms to make optimal decisions. AI systems in mining can develop compliance and regulatory requirements, enhance operational efficiency, and reduce manpower (Mangal, Sarkar, \& Paul, 2017). AI can perform the tasks of controlling costs for mineral exploration as well as the monumental challenge to make a competitive and productive company.

\section{Literature Review}

Coal mines are the sources of primary energy resources in the development of a society. Failed experiences can help enhance the protection in the mining process (Zhou, Li, \& Wu, 2012). Accidents in industries mostly occurred due to a series of failures or mistakes (Al-Shanini, Ahmad, \& Khan, 2014). Many effective countermeasures can make great contributions in mining, such as improving safety enactment and building autonomous coal mine safety monitoring system (Chen et al., 2012). Mehmet Sari said that mining accidents are unplanned events and can be measured by stochastic modelling by using two variables' levels of hazard and probability of occurrence (Sari et al., 2009). Badri managed practically all risks of mining by hazard concentration and Analytic Hierarchy Process (AHP) (Badri, Nadeau, \& Gbodossou, 2013). The unpredictable roof fall hazards were studied by Liu \& $\operatorname{Li}(2014)$ and a distribution function was constructed by using neural network to predict annual roof fall. Ljiljana proposed a new risk assessment tool by using a semi-quantitative estimation for 
the risk of explosion by using the risk index and risk matrix (Pejic et al., 2013). Jiqiang and Litao performed a comprehensive evaluation of coal mine safety based on uncertain random variables and chance measure (Chen et al., 2014). Xiaosan Ge proposed the concept of Smart mining with the use of engineering and the internet of things technology. He presented a complete overview between environment and sustainable mineral resource exploitation with the synchronization of the smart mining production process (Ge et al., 2018). Yu Jiang invented some unmanned electric locomotives to track underground position by using WSN. They also used AI to develop an advanced control system for unmanned electric locomotive systems (Jiang et al., 2017). Hu et al. (2013) used the Controller Area Network (CAN) bus and ZigBee technology to build an intelligent monitoring system. He observed the process of mining effectively and warned miners instantly in the event of gas leakage. Coal-excavation automation was performed by Georgi by making a recognition system in the shearer loader which turned the mining into economical human-free coal mining (Nalbantov et al., 2010). Zhang et al. (2014) built an integrated environmental monitoring system by using Cable Monitoring System (CMS) and WSN. He also performed some real experiments to check the feasibility of the new tool. Saaniya and Anurag appraised the risk of fire based on the forecasts using Machine Learning outputs (Harini, Krishna, \& Bhargav, 2019). Hebblewhite (2009) said that only technology is not sufficient to beat the risks in coal mining; proper education and training are also essential for mine safety. Zhang et al. (2012) discussed the concept of the Internet of Things for informational interchange and communication by using RFID, laser scanner, infrared sensor, and GPS. BHP and RioTinto started the use of the autonomous trucks to reduce the operation costs. These trucks can work 24/7 to increase the efficiency of operations (Dyson, 2017). Artificial Intelligence and Machine learning can produce a modish revolution to the mining industry by using intelligent systems (Hyder, Siau, \& Nah, 2019). Singh et al. (2016) presented a real time monitoring system using AI and WSNs.

\section{Research Methodology}

A systematic review and statistical analysis are performed to answer all the research questions. Following we have developed some research questions to focus on the main objective of the paper.

RQ1: What are the recent technology trends and how are they helping in the risk assessment in mining industry?

RQ2: How will AI make mining safer and more economical?

RQ3: What will be the future of mining by adopting AI techniques?

Scopus, Yahoo, Baidu, and Google were used as search engines to search the related statistical data and other articles. In the first section, we have identified the mining industry accident, damages, and production statistics by studying and analyzing the statistical reports and graphs given by Mine Safety and Health 
Administration (MSHA) USA, Directorate General of Mines Safety India, State Administration of Coal Mine Safety China, NSW Government Australia and some other sectors in different countries. More than 30 research papers were reviewed for this research. Most papers consisted of the research keywords such as "risk assessment", "risk management", "safety measurements in mining", "AI and coal mining", "Smart Mining" and "economic impacts of coal mining". Main sections which were analyzed in all the research papers and statistical reports can be seen in Figure 4.

Accident statistics and incident records were mostly collected from Mine Safety and Health Administration (MSHA) USA, Directorate General of Mines Safety India and State Administration of Coal Mine Safety China. Author also visited the Duki and Mach-Kingriin in Pakistan to collect the data by personal interviews. Main objective of these interviews is to collect the data about accidents and its causes during mining. Through interviews and careful review of the literature, we found that failures and accidents normally occured due to:

- Improper management of haulage road

- Improper management of ropes

- Poor management of tubs and drawbar

- Careless workers

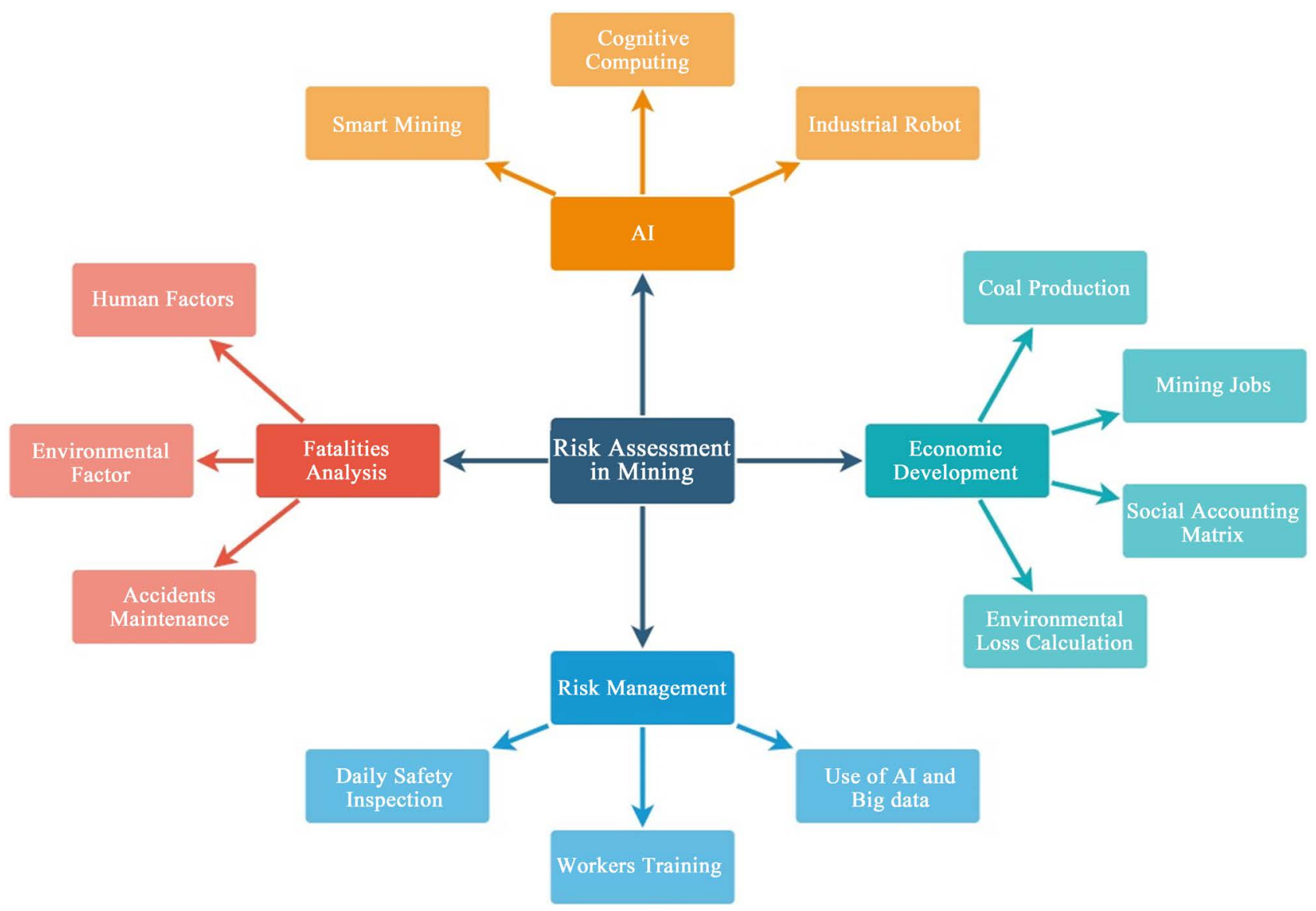

Figure 4. Main topics which are covered in systematic review. 
- Lack of technology

All the research papers on modern technology in underground mining showed that by using AI, big data and machine learning, we can improve:

- Real-time data monitoring

- Augmented Reality usage to reduce the cost

- Use of autonomous vehicles, automated drones, and drillers

Coal mine safety is vital to remove the danger and provide a safer roadway for miners. In short, AI can assist in management of environmental hazards and safety for both miners and land. But there are still challenges in controlling sensors and mining robotics.

\section{Results and Discussion}

By studying statistical reports shared by mining departments, we concluded that mining accidents occurred in the past due to poor supervision, inadequate implementation of enactment, lack of security consciousness, and inadequate safety education (Jung \& Choi, 2021). What are the factors which make mining threatening? Poor lighting, inadequate working space, toxic gases, radioactive materials, dust scraps from metals, poor air supply, unstable roofs, and use of explosives (Hyder, Siau, \& Nah, 2019). In 2019, the number of fatalities in China was 248 , on the other hand, the number in USA was reduced to 12 which is 20 times less than China and 96 in India which is 2.58 times as many as that of China. Coal Fatalities in USA from 2010 to 2019 can be seen in Figure 5.

China is leading with respect to the death rate in coal mines amongst USA, China, and India which is provided in Figure 6. We also did a statistical analysis of these three countries' death rates. Overall, China is at the top in using the

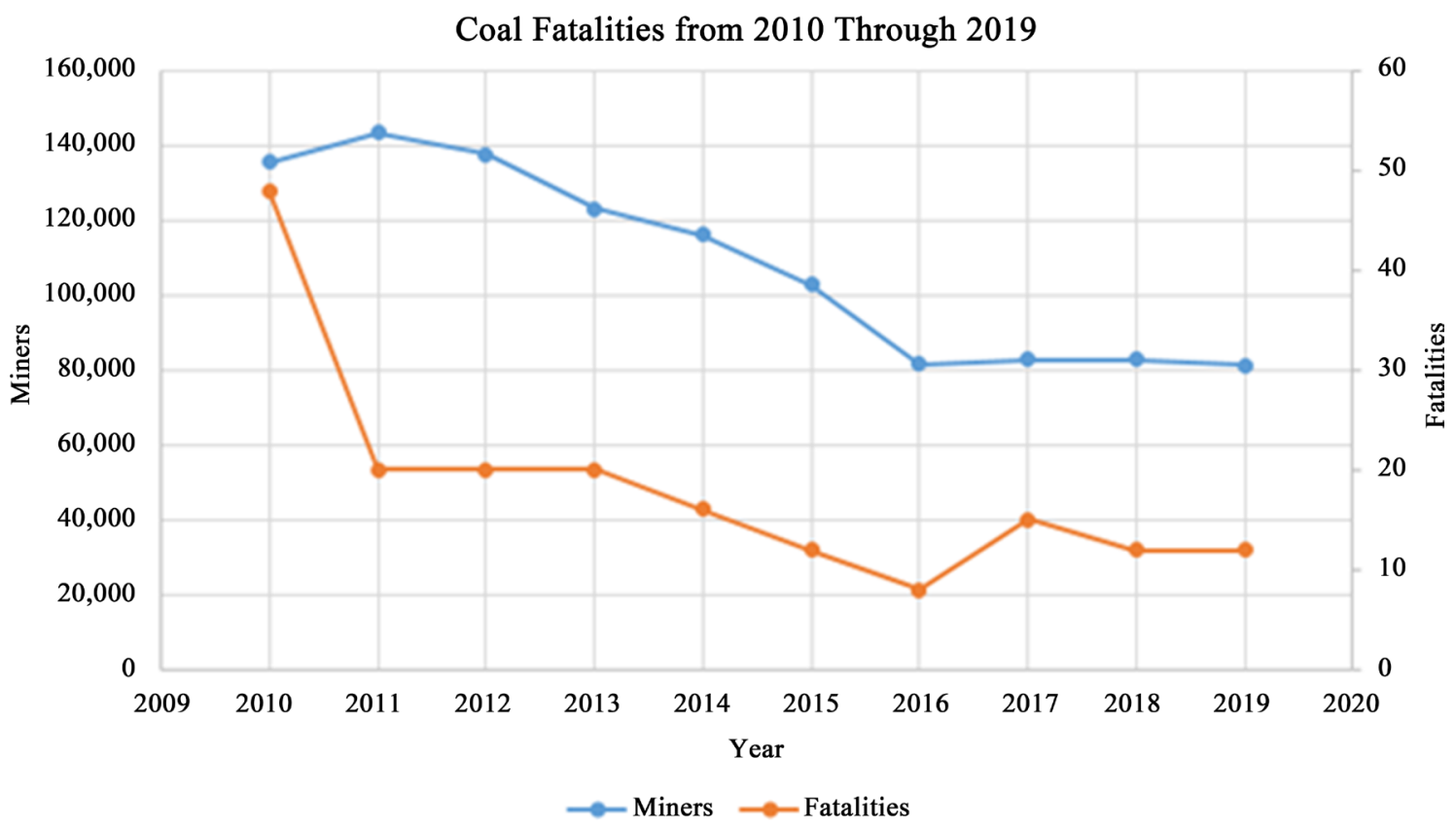

Figure 5. Coal Fatalities in USA from 2010 to 2019. 
Fatalities Rate in three major countries

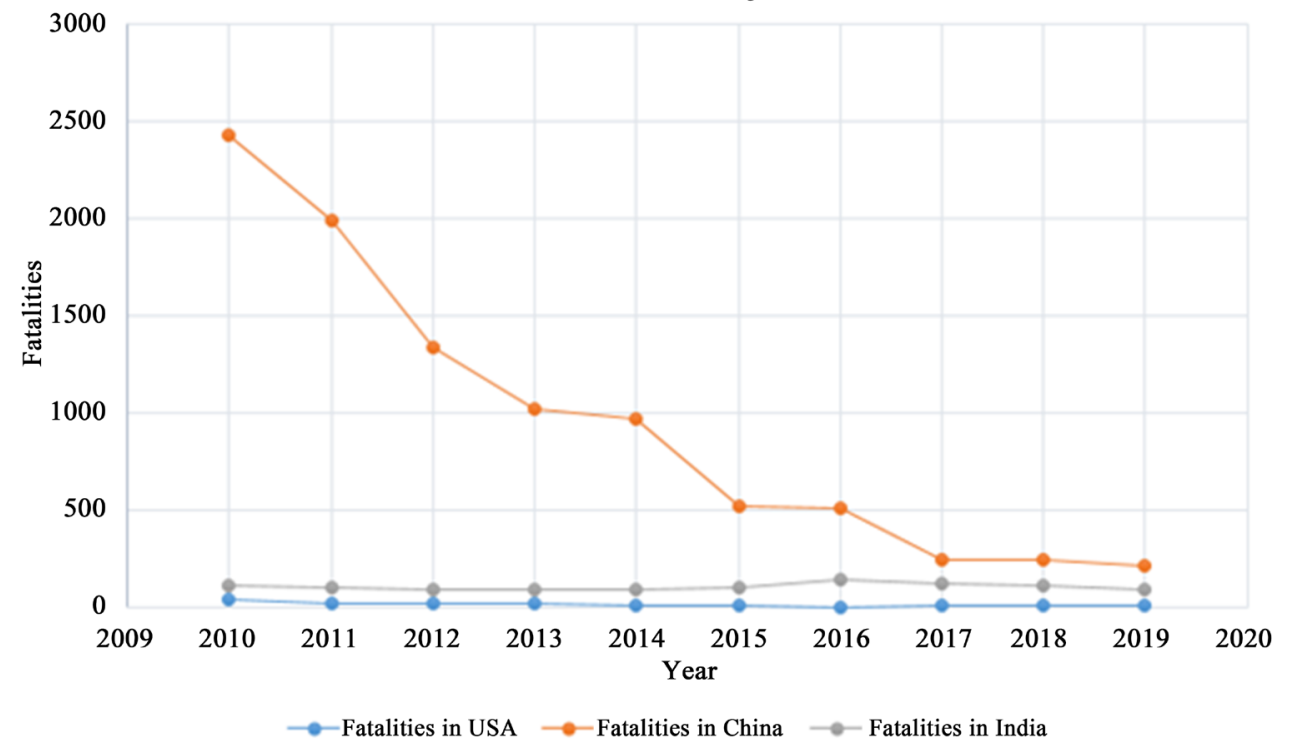

Figure 6. Fatalities Rate in 3 major countries.

most advanced technologies such as scanning roadway technology, optoelectronic technology, intelligent control technology, and 3D visual technology (Wang \& Huang, 2017). AI with big data can help in collecting the data about the roof floor conditions, fatality alert, ground pressure and methane effusion in the underground mining operation by use of mining robotics and sensors. Machine Learning, AI and Deep learning can transform mining into a safer and more fruitful business.

AI systems with a fraction of the data generated in the laboratory can be fed as training data and then used to predict the behavior of the model based on that data. These predictions can be tested against some data generated experimentally and correction can be applied, and an AI system can be retested to improve the accuracy of the results. In India, Saaniya and Anurag developed a Machine Learning Algorithm by using data collected from 12 mines and some factors in hand. They have constructed the results by using Extra Tree, Random Forest and logistic regression (Harini, Krishna, \& Bhargav, 2019). If same kind of algorithm is performed on international level, then fire incidents can be predicted more precisely. Singh et al. (2016) used the wireless sensor networks in November 2016 to avoid accidents during mining. Same kind of intelligent techniques can be performed with advanced $5 \mathrm{G}$ wireless sensors and an actual real time monitoring system can be developed practically.

Despite the fact that autonomous technologies and AI in mining began a decade ago, the progress of implementation of these technologies is very slow and a number of complexities and failures have been encountered along the way. One of the major problems while implementing technology is the resistance of workers, administrators and even Artificial Intelligence scientists who are not certain about the effects of this technology on the economy, jobs, social systems, work- 
ing relationships and social makeup (Kappal, 2017; Siau, 2018). The resistance is usually based on fear of losing jobs, AI and autonomous systems' unambiguous behavior, irregular circulation of wealth and assets, complex communications and associations with technology, and uncertain future of technology implementation (Kappal, 2017; Siau \& Wang, 2018).

It is quite obvious that group and individual's decision making can be handled by different technologies employing AI (Jeswiet \& Szekeres, 2016). The second biggest challenge for the implementation of such technologies is the requirement of capital for operations and automation of systems. The changing nature of mining is considered as one of the biggest challenges in the way of implementing these machine learning technologies (Knickrehm, 2018; Peng, 2015). There are several variables in motion that conduct mining operations and are mostly erratic, hence making it very difficult to implement complete autonomous systems and operations. Environmental circumstances, rapid movement of water and gases, stress and strain regimes, compressed space, and difficulty in transforming signals underground from systems and to machines are some of the aspects that must be solved before commercializing these AI and machine learning systems implementation in the Mining industry. Some main challenges are highlighted below:

- Reliable data availability is difficult to come by as most of the data gathering is ambiguous.

- Probability of earning profits and the requirement of formation and design of system implementation are not very well measured.

- Existing consistency of systems.

- Hard to build a model because of changing nature of the mining environment.

- Economic problems and the requirement of big investment for automation.

- Unavailability of skilled workers to implement, maintain, and operate these systems.

- Uncertainty of success since it has never been used at an industrial scale specifically in the mining industry.

Many researchers agree that these technologies could deliver outstanding results in dangerous and difficult mining operations. AI Technology in Coal Mining has many benefits such as environmental protection, energy efficiency and much more which can be seen in Figure 7 . We need to work closely with C-Level Management, legislators, AI practitioners, policy makers, investors, AI system developers, researchers and social scientists and most importantly labor representatives to negotiate to solve the psychological, economic, and social issues regarding these technologies.

\section{Conclusion}

Accidents happen every day underground due to roofs collapsing or explosions from hazardous gases. Risk assessment process is a challenging assignment in 


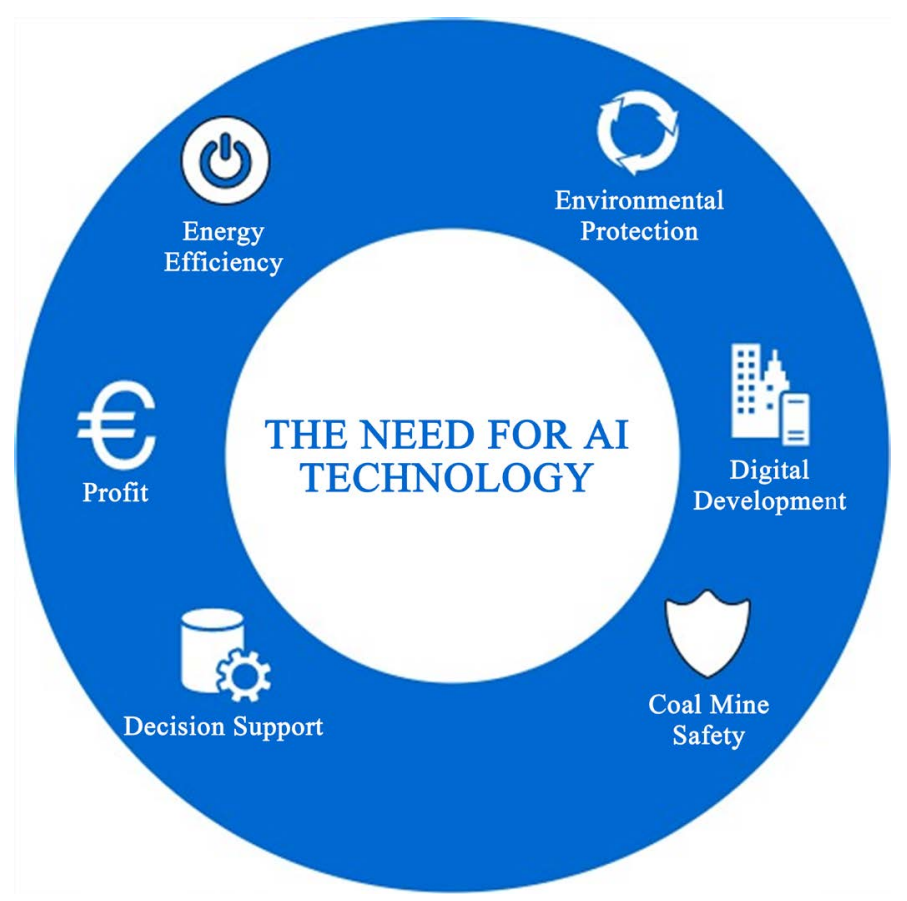

Figure 7. Fatalities Rate in 3 major countries.

underground mining. Autonomous technologies like machine learning and AI can bring a whole new revolution in the mining industry by improving productivity, efficiency, and reduction in operational cost. We can use more advanced sensors to detect the humidity, temperature, and methane values underground. On the other hand, advanced systems can help the researchers to get more data for training and testing the Machine Learning algorithms. Both AI and ML can accommodate the mandatory safety prerequisite to avoid accidents. Moreover, the mining industry is gradually moving towards implementation of these intelligent systems, specifically in the field of autonomous vehicles and automated machines.

However, to understand the complete possible potential of these technologies in numerous mining processes requires more intensive hard work, huge initial investment, and availability of skilled personnel. Future researchers can work on finding a plan to merge the future technology with equipment reliability to increase the coal production with bigger efficiency. They can try to cover up the challenges and hurdles while implementing these intelligent systems by getting more information through open-ended surveys in future studies.

\section{Funding}

National Natural Science Foundation of China under grant (No. 71971003); the Major Program of Humanities and Social Sciences in Colleges and Universities of Anhui Province, China under grant (No. SK2019ZD09).

\section{Conflicts of Interest}

The authors declare no conflicts of interest regarding the publication of this paper. 


\section{References}

Al-Shanini, A., Ahmad, A., \& Khan, F. (2014). Accident Modelling and Analysis in Process Industries. Journal of Loss Prevention in the Process Industries, 32, 319-334. https://doi.org/10.1016/j.jlp.2014.09.016

Badri, A., Nadeau, S., \& Gbodossou, A. (2013). A New Practical Approach to Risk Management for Underground Mining Project in Quebec. Journal of Loss Prevention in the Process Industries, 26, 1145-1158. https://doi.org/10.1016/j.jlp.2013.04.014

Balat, H. (2007). Role of Coal in Sustainable Energy Development. Energy Exploration and Exploitation, 25, 151-174. https://doi.org/10.1260/014459807782009169

Chen, H., Qi, H., Long, R., \& Zhang, M. (2012). Research on 10-Year Tendency of China Coal Mine Accidents and the Characteristics of Human Factors. Safety Science, 50, 745-750. https://doi.org/10.1016/j.ssci.2011.08.040

Chen, J., Ma, L., Wang, C., Zhang, H., \& Ha, M. (2014). Comprehensive Evaluation Model for Coal Mine Safety Based on Uncertain Random Variables. Safety Science, 68, 146-152. https://doi.org/10.1016/j.ssci.2014.03.013

Dyson, N. (2017). BHP to Double Autonomous Trucks at Jimblebar. Mining Magazine.

Garside, M. (2021). Coal-Statistics \& Facts. https://www.statista.com/topics/1051/coal/

Ge, X., Su, S., Yu, H., Chen, G., \& Lu, X. (2018). Smart Mine Construction Based on Knowledge Engineering and Internet of Things. International Journal of Performability Engineering, 14, 1060. https://doi.org/10.23940/ijpe.18.05.p25.10601068

Harini, M., Krishna, B., \& Bhargav, S. (2019). User Data Driven Recommendation for Location.

https://www.ijitee.org/wp-content/uploads/papers/v8i11S/K122309811S19.pdf

Hebblewhite, B. (2009). Mine Safety-Through Appropriate Combination of Technology and Management Practice. Procedia Earth and Planetary Science, 1, 13-19. https://doi.org/10.1016/j.proeps.2009.09.005

Hu, S., Tang, C., Yu, R., Liu, F., \& Wang, X. (2013, November). Intelligent Coal Mine Monitoring System Based on the Internet of Things. In 2013 3rd International Conference on Consumer Electronics, Communications and Networks (pp. 380-384). New York: IEEE. https://doi.org/10.1109/CECNet.2013.6703350

Hyder, Z., Siau, K., \& Nah, F. (2019). Artificial Intelligence, Machine Learning, and Autonomous Technologies in Mining Industry. Journal of Database Management (JDM), 30, 67-79. https://doi.org/10.4018/JDM.2019040104

Jeswiet, J., \& Szekeres, A. (2016). Energy Consumption in Mining Comminution. Procedia CIRP, 48, 140-145. https://doi.org/10.1016/j.procir.2016.03.250

Jiang, Y., Li, Z., Yang, G., Zhang, Y., \& Zhang, X. (2017). Recent Progress on Smart Mining in China: Unmanned Electric Locomotive. Advances in Mechanical Engineering, 9. https://doi.org/10.1177/1687814017695045

Jung, D., \& Choi, Y. (2021). Systematic Review of Machine Learning Applications in Mining: Exploration, Exploitation, and Reclamation. Minerals, 11, 148.

https://doi.org/10.3390/min11020148

Kappal, S. (2017). The Biggest Challenges in Implementing AI. https://dzone.com/articles/the-biggest-challenges-in-implementing-ai

Knickrehm, M. (2018). How Will AI Change Work? Here Are 5 Schools of Thought. Harvard Business Review.

Liu, Q. L., \& Li, X. C. (2014). Modeling and Evaluation of the Safety Control Capability of 
Coal Mine Based on System Safety. Journal of Cleaner Production, 84, 797-802. https://doi.org/10.1016/j.jclepro.2013.11.048

Mangal, A., Sarkar, F., \& Paul, P. (2017) A Step toward Achieving a Zero Accident Potential in Indian Mining Industry (p. 432). Mongolia: Ereen Gold Ore Deposit.

Nalbantov, G. I., Smirnov, E. N., Nalbantov, D. I., Weiss, G., Nienhaus, K., Warcholik, M., \& Mavroudis, F. (2010). Image Mining for Intelligent Autonomous Coal Mining. Industrial Conference on Data Mining-Poster and Industry Proceedings, Berlin, Germany, July 2010, 17-23.

Pejic, L. M., Torrent, J. G., Querol, E., \& Lebecki, K. (2013). A New Simple Methodology for Evaluation of Explosion Risk in Underground Coal Mines. Journal of Loss Prevention in the Process Industries, 26, 1524-1529. https://doi.org/10.1016/j.jlp.2013.08.021

Peng, S. S. (2015). Topical Areas of Research Needs in Ground Control-A State of the Art Review on Coal Mine Ground Control. International Journal of Mining Science and Technology, 25, 1-6. https://doi.org/10.1016/j.ijmst.2014.12.006

Sari, M., Selcuk, A. S., Karpuz, C., \& Duzgun, H. S. B. (2009). Stochastic Modeling of Accident Risks Associated with an Underground Coal Mine in Turkey. Safety Science, 47, 78-87. https://doi.org/10.1016/j.ssci.2007.12.004

Siau, K. (2018). Education in the Age of Artificial Intelligence: How Will Technology Shape Learning. The Global Analyst, 7, 22-24.

Siau, K., \& Wang, W. (2018). Building Trust in Artificial Intelligence, Machine Learning, and Robotics. Cutter Business Technology Journal, 31, 47-53.

Singh, A. N., Kumar, R. R., Kumar, V., \& Gautam, V. (2016). Safety of Underground Coal Mine Using Artificial Intelligence and Wireless Sensor Network. International Journal of Engineering and Computer Science, 5, Article ID: 18940. https://doi.org/10.18535/ijecs/v5i11.38

Tripathy, D. P., \& Ala, C. K. (2018). Identification of Safety Hazards in Indian Underground Coal Mines. Journal of Sustainable Mining, 17, 175-183.

https://doi.org/10.1016/j.jsm.2018.07.005

U.S. Department of Labor (n.d.-a). Fatality Reports. U.S. Department of Labor Website. https://www.msha.gov/data-reports/fatality-reports

U.S. Department of Labor (n.d.-b). Mining Industry Accident, Injuries, Employment, and Production Statistics and Reports. U.S. Department of Labor Website. https://arlweb.msha.gov/ACCINJ/accinj.htm

Wang, J., \& Huang, Z. (2017). The Recent Technological Development of Intelligent Mining in China. Engineering, 3, 439-444. https://doi.org/10.1016/J.ENG.2017.04.003

Zhang, Y. H., Fu, G. H., Zhao, Z. G., Huang, Z. A., Li, H. C., \& Yang, J. X. (2012). Discussion on Application of IOT Technology in Coal Mine Safety Supervision. Procedia Engineering, 43, 233-237. https://doi.org/10.1016/j.proeng.2012.08.040

Zhang, Y., Yang, W., Han, D., \& Kim, Y. I. (2014). An Integrated Environment Monitoring System for Underground Coal Mines-Wireless Sensor Network Subsystem with Multi-Parameter Monitoring. Sensors, 14, 13149-13170.

https://doi.org/10.3390/s140713149

Zhou, Z., Li, Q., \& Wu, W. (2012). Developing a Versatile Subway Construction Incident Database for Safety Management. Journal of Construction Engineering and Management, 138, 1169-1180. https://doi.org/10.1061/(ASCE)CO.1943-7862.0000518 